\title{
Pseudomonas aeruginosa Type III Secretion System Virulotypes and Their Association with Clinical Features of Cystic Fibrosis Patients
}

This article was published in the following Dove Press journal: Infection and Drug Resistance

\author{
Edilene do Socorro \\ Nascimento Falcão Sarges (iD) 1,2 \\ Yan Corrêa Rodrigues (iD) \\ Ismari Perini Furlaneto ${ }^{3}$ \\ Marcos Vinicios Hino de \\ Melo iD ' \\ Giulia Leão da Cunha Brabo ${ }^{4}$ \\ Kátia Cilene Machado Lopes (1) ${ }^{2}$ \\ Ana Judith Pires Garcia \\ Quaresma $^{4}$ \\ Luana Nepomuceno Godim \\ Costa Lima ${ }^{1,4}$ \\ Karla Valéria Batista Lima (iD ${ }^{1,4}$ \\ 'Programa de Pós-graduação em Biologia \\ Parasitária na Amazônia, Universidade do \\ Estado do Pará, Belém, Pará, Brazil; \\ ${ }^{2}$ Hospital Universitário João de Barros \\ Barreto, Universidade Federal do Pará, \\ Belém, Pará, Brazil; ${ }^{3}$ Mestrado \\ Profissional em Ensino em Saúde - \\ Educação Médica, Centro Universitário \\ do Pará, Belém, Pará, Brazil; ${ }^{4}$ Instituto \\ Evandro Chagas, Seção de Bacteriologia e \\ Micologia, Ananindeua, Pará, Brazil
}

Correspondence: Edilene do Socorro Nascimento Falcão Sarges Ambulatório de Fibrose Cística, Hospital Universitário João de Barros Barreto, Universidade Federal do Pará, Rua dos Mundurucus, 4487, Bairro Guamá, CEP 66075-000, Belém, Pará, Brazil Tel +5591993484649

Email edifalcao@ufpa.br

Karla Valéria Batista Lima Evandro Chagas Institute, $\mathrm{Br} 316, \mathrm{~km} \mathrm{7,} \mathrm{s/}$ n., Ananindeua, Pará, Brazil Tel +559132142116

Email karlalima@iec.pa.gov.br
Purpose: Pseudomonas aeruginosa appears as the main pathogen in cystic fibrosis (CF) involved in recurrent pneumonia and pulmonary exacerbations. The type III secretion system (T3SS) is one of its main determinants of virulence and is associated with poor clinical progression and increased mortality. This study determined the relationship of clinical features of patients with $\mathrm{CF}$ and $P$. aeruginosa T3SS virulotypes.

Materials and Methods: From January 2018 to March 2019, P. aeruginosa were isolated from sputum and/or oropharyngeal swabs. T3SS markers (exoS, exoU, exoT and exoY) were detected by PCR. Clinical severity according to Shwachman-Kulckycki score and spirometry data were associated with T3SS virulotypes.

Results: A total of 49 patients had positive cultures for $P$. aeruginosa. T3SS virulence-related markers were detected as follows: exoS 97.9\% $(n=48)$, exoU $63.2 \%(n=31)$, exoT $95.9 \%$ $(\mathrm{n}=47)$ and $\operatorname{exoY} 97.9 \%(\mathrm{n}=48)$. The prevalence of $\operatorname{exoS} /$ exo $U^{+}$virulotype was higher than previously reported in CF settings, being detected in $61.2 \%$ of the evaluated isolates, present in $70 \%$ of intermittent infections and with a significantly higher frequency in cases of exacerbations. The presence of exoU in chronic infection was not associated with poor clinical results. In chronic infections, the exoS $/$ exo $U$ virulotype prevailed $(77.8 \%)$ and was associated to worse clinical results according to the Shwachman-Kulckycki score and spirometric.

Conclusion: Our findings revealed a high prevalence of the atypical $\operatorname{exoS}^{+} / \operatorname{exo}^{+}$virulotype among $P$. aeruginosa isolates from patients with $\mathrm{CF}$, which was associated with intermittent infection and early clinical alterations, while the exo $S^{+} / \operatorname{exo} U$ virulotype was associated with chronic infection and worse clinical results. Finally, the presented data highlight the relevance of T3SS virulence markers in the clinical progression and disease severity in CF patients.

Keywords: virulence genes, type III secretory system, exoS, exoU, exoT, exoY

\section{Introduction}

Cystic fibrosis (CF) is an autosomal recessive disorder, which mutation on the cystic fibrosis transmembrane conductance regulator (CFTR) gene negatively affects the encoding of a protein that regulates chlorine and sodium transmembrane transport to intracellular medium, causing extracellular dehydration, electrolyte changes in sweat, production of thick mucus, and consequent obstruction of the airways, pancreatic, biliary and efferent pathways. In Brazil, it is estimated that the incidence of $\mathrm{CF}$ is 1:7.576 live births; however, due to its great population miscegenation, it presents regional differences, with higher values observed in Brazilian southern states. ${ }^{1-3}$ 
The clinical presentation is variable, mostly occurring progressive respiratory disease and malnutrition, acute pulmonary exacerbations, increased cough, changes in the appearance of sputum secretions, fever, decrease in spirometric data, radiological changes and weight loss, leading to progressive respiratory and functional impairment and, later, respiratory failure. Thus, chronic lung disease remains the main responsible for the high morbidity and mortality among CF patients. ${ }^{3-5}$

Pseudomonas aeruginosa is one of the most frequent and mortality-related pathogens in CF patients, causing recurrent lower respiratory tract infections and/or chronic lung colonization, which accelerates the deterioration of lung function and nutritional status. The pathogen eradication and disease severity are associated with its impressive genetic and metabolic plasticity, antimicrobial resistance and secretion of virulence exoproducts. ${ }^{6-10}$

Pathogenicity in $P$. aeruginosa is related to virulence factors that contribute to host persistence and invasion. Shared by several Gram-negative bacteria species, the type III secretion system (T3SS) is one of the most clinically relevant virulence determinants in $P$. aeruginosa, which acts through the translocation of up to four exotoxins (ExoS, ExoU, ExoT and ExoY) to the host cell by a needle-like appendix. The high virulence potential conferred by secretion ExoS and ExoU contributes to the deterioration of lung tissue and higher mortality probability. ExoT and ExoY play a minor role in virulence, as in vivo and in vitro assays have demonstrated little cytotoxicity. ${ }^{11,12}$ These effector proteins are encoded by exoS, exoU, exoT and exo $Y$ genes, respectively, and are variably detected in $P$. aeruginosa, where exoS, exoT and exo $Y$ are found in approximately all strains, while exoU is detected less frequently for being associated with a pathogenicity island (PAPI-2) not belonging to the core genome of $P$. aeruginosa. In addition, exoS and exoU genes are usually mutually exclusive, being the $\operatorname{exoS}^{+} / \mathrm{exoU}^{+}$virulotype rarely detected. ${ }^{10-12}$

Previously, several studies have associated the $\operatorname{exoS}^{+} /$ exo $U$ virulotype with $P$. aeruginosa causing chronic infection in CF patients and most of exoS $/$ exoU $U^{+}$virulotype have been reported on non-CF strains. ${ }^{13-19}$ In addition, studies evaluating the association between clinical features of patients and T3SS virulotype were performed including $P$. aeruginosa clinical isolates causing different types of acute infections. ${ }^{20-22}$ Therefore, the objective of this study was to determine the prevalence of T3SS genes in $P$. aeruginosa isolates from $\mathrm{CF}$ patients at a referral center in the Brazilian Amazon, as well as its association with patients' clinical features.

\section{Materials and Methods Study Design and Inclusion Criteria}

In this cross-sectional, descriptive and analytical study, 112 CF patients treated at a CF referral center in Pará state, Brazilian Amazon, which had positive cultures for nonspecific germs from oropharynx swab and/or sputum from January 2018 to March 2019, were included. Patients were grouped according to $P$. aeruginosa infection status as chronic, intermittent or infection-free. Chronic infection was defined as a patient with $>50 \%$ of cultures positive for P. aeruginosa in the last 12 months or with the presence of 3 or more positive cultures in a period of 6 months, according to the routine adopted by the referral center. ${ }^{4}$

\section{Bacterial Isolates}

All isolates were plated on MacConkey Agar media and incubated for $24 \mathrm{~h} / 35^{\circ} \mathrm{C}$ for observation of colony morphology, presence/or absence of mucoid phenotype and Gram staining. Identification of isolates was performed on an automated VITEK-2 system (bioMérieux, Marcy l'Etoile, France) and complemented by phenotypical and biochemical assays such as oxidase test, absence of carbohydrate fermentation on triple sugar iron agar, oxidative behavior on Hugh Leifson medium and the cytochrome oxidase reaction.

\section{Determination of Severity Degree and Spirometry Data}

The variables of the Shwachman-Kulckycki score assessed the degree of clinical severity from CF patients, considering general activity assessment (0-25), radiological findings (0-25), physical examination (0-25) and nutritional status ( $0-25)$. A total score ranging from 86 to 100 points expressed an "excellent" evolution, 71-85 "good", 56-70 "mild", 41-55 "moderate" and <40 "severe". ${ }^{23}$ Spirometric data were collected from medical records, being evaluated the Forced Expiratory Volume in the 1st second $\left(\mathrm{FEV}_{1}\right)$, Forced Vital Capacity $(\mathrm{FVC})$, Tiffenau Index $\left(\mathrm{FEV}_{1} / \mathrm{FVC}\right)$ and Intermediate Forced Expiratory Flow $\left(\mathrm{FEF}_{25-75 \%}\right)$ for analysis of pulmonary function. ${ }^{24}$

\section{Molecular Detection of T3SS Genes}

Genomic DNA was obtained from isolates of the last positive cultures of patients using the PureLink TM Genomic 
DNA Mini Kit (Invitrogen TM, Carlsbad, USA) following the manufacturer's recommendations. T3SS-related genes exoS, exoU, exoT and exoY - were amplified by PCR as previously described by Finnan et $\mathrm{al}^{19}$ and $\mathrm{Zhu}$ et $\mathrm{al},{ }^{25}$ with modifications (Table 1). Each PCR mixture was prepared to a final volume of $25 \mu \mathrm{L}, 1 \mathrm{x}$ Master mix GoTaq $^{\circledR}$ DNA Polymerase (Promega, Wisconsin, USA), 1x Q-solution (Qiagen, Hilden, Germany), $0.5 \mu \mathrm{M}$ of each primer and DNA template, followed by amplification in Veriti Thermocycler (Applied Biosystem, USA) under the following conditions: $95^{\circ} \mathrm{C}$ for 2 minutes; followed by 35 cycles at $95^{\circ} \mathrm{C}$ for 1 minute, $60^{\circ} \mathrm{C}$ for 45 seconds, $72^{\circ} \mathrm{C}$ for 1 minute and a final extension step at $72^{\circ} \mathrm{C}$ for 7 minutes. The observation of PCR products under ultraviolet light was performed after electrophoresis on 1\% agarose gel stained with Syber ${ }^{\circledR}$ Safe stain (Invitrogen TM, Carlsbad, USA) at 100 V. P. aeruginosa ATCC 27,853 and PA14 strains were used as positive controls.

\section{Statistical Analysis}

The results were treated using descriptive statistics and expressed using central tendency and dispersion measures appropriate to each distribution. Data normality was tested by the Shapiro-Wilk test. The independence between categories of qualitative variables and groups was tested using the G-test of independence, followed by the Chi-square residue analysis in case of statistical significance. The comparison of ordinal or numerical variables with asymmetric distribution between groups was performed with Kruskal-Wallis variance analysis, complemented by Dunn's post-test in case of significance. Values of $P \leq 0.05$ were considered statistically significant. All analyses were performed using the statistical software BioEstat ${ }^{\circledR} 5.4 .^{26}$

\section{Ethics Statement}

Samples included in this study were obtained during the routine laboratory procedure at the $\mathrm{CF}$ referral center. This study was approved by the Ethics Committee of Hospital Universitário João de Barros Barreto $\left(\mathrm{N}^{\circ}\right.$ 1.910.716) and registered in the National System of Management of Genetic Heritage and Associated Traditional Knowledge (SisGen; No AF44CCB).

\section{Results}

The referral center had $136 \mathrm{CF}$ patients active in the treatment program. One hundred and twelve patients with oropharyngeal and/or sputum swab cultures were included, of which 49 (43.7\%) had positive cultures for $P$. aeruginosa and classified as chronic infection $(\mathrm{n}=23)$, intermittent infection $(n=26)$ and infection-free $(n=63)$. The number of annual exacerbations was significantly higher in chronically infected patients when compared to infection-free patients (Table $2 / p=0.0087$ ). Patients with chronic infection and infection-free were similar in age and both were older than those with intermittent infection (Table $2 / p=0.0023$ ). Regarding age at diagnosis, chronically infected patients tended to be diagnosed later when compared to patients with intermittent infection (Table $2 / p$ $=0.0025$ ).

Comparing the distribution of cases according to the severity category, a significantly higher frequency of "mild" and "severe" cases was observed among patients with chronic infection. In addition, it was observed a significantly lower frequency of cases with "excellent" classification among patients with chronic infection and of cases classified as "mild", "moderate" and "severe" among infection-free patients (Table $3 / p<0.0001$ ).

Table I Primers Sequences Used in the Molecular Detection of T3SS Related-Genes

\begin{tabular}{|l|l|l|l|}
\hline Gene & Primers Sequence & Amplicons Size (bp) & Reference \\
\hline exoS & $\begin{array}{l}\text { F: 5'-CGTCGTGTTCAAGCAGATGGTGCTG-3' } \\
\text { R: 5'-CCGAACCGCTTCACCAGGC-3' }\end{array}$ & 444 & Finnan et al $^{19}$ \\
\hline exoT & $\begin{array}{l}\text { F: 5'-CAATCATCTCAGCAGAACCC-3' } \\
\text { R: 5'-TGTCGTAGAGGATCTCCTG-3' }\end{array}$ & 1159 & \\
\hline exoY & $\begin{array}{l}\text { F: 5'-TATCGACGGTCATCGTCAGGT-3' } \\
\text { R: 5'-TTGATGCACTCGACCAGCAAG-3' }\end{array}$ & 1035 & Zhu et al ${ }^{25}$ \\
\hline exoU & $\begin{array}{l}\text { F: 5'-GGGAATACTTTCCGGGAAGTT-3' } \\
\text { R: 5'-CGATCTCGCTGCTAATGTGTT-3' }\end{array}$ & 428 & \\
\hline
\end{tabular}

Abbreviation: bp, base pairs 
Table 2 P. aeruginosa Infection Profile According to the Number of Exacerbations/Year, Age and Age at Diagnosis

\begin{tabular}{|c|c|c|c|c|}
\hline \multirow[t]{2}{*}{ Variable } & \multicolumn{3}{|l|}{ Groups } & \multirow[t]{2}{*}{ p-value* } \\
\hline & $\begin{array}{l}\text { Chronic Infection } \\
n=23\end{array}$ & $\begin{array}{l}\text { Intermittent Infection } \\
\mathrm{n}=26\end{array}$ & $\begin{array}{l}\text { Infection-Free } \\
n=63\end{array}$ & \\
\hline \multicolumn{5}{|c|}{ Number of exacerbations/year } \\
\hline Min. - Max. & $0-4,0$ & $0-2,0$ & $0-4,0$ & $0,0087^{\dagger}$ \\
\hline Median (DIQ) & $0(2,0)^{a}$ & $0(1,0)$ & $0(0)^{a}$ & \\
\hline P25/P75 & $0 / 2,0$ & $0 / 1,0$ & $0 / 0$ & \\
\hline $\mathrm{CV} \%$ & 127,5 & $|4|, 2$ & 241,9 & \\
\hline \multicolumn{5}{|l|}{ Age (years) } \\
\hline Min. - Max. & $2,0-63,0$ & $1,0-38,0$ & $0,2-70,0$ & $0,0023^{\dagger}$ \\
\hline Median (DIQ) & $21,0(17,0)^{a}$ & $9,0(8,3)^{a, b}$ & $15,0(12,0)^{\mathrm{b}}$ & \\
\hline $\mathrm{P} 25 / \mathrm{P} 75$ & $9,0 / 26,0$ & $7,0-15,3$ & $\mathrm{II}, 0 / 23,0$ & \\
\hline $\mathrm{CV} \%$ & 73,5 & 66,1 & 73,3 & \\
\hline \multicolumn{5}{|c|}{ Age at diagnosis (years) } \\
\hline Min. - Max. & $0,3-62,0$ & $0, I-30,0$ & $0,1-64,0$ & $0,0025^{\dagger}$ \\
\hline Median (DIQ) & $12,0(13,0)^{\mathrm{a}}$ & $3,0(5,5)^{\mathrm{a}}$ & $6,0(9,0)$ & \\
\hline $\mathrm{P} 25 / \mathrm{P} 75$ & $6,0 / 19,0$ & $0,8-6,3$ & $2,0 / 11,0$ & \\
\hline CV\% & 101,6 & 135,4 & 133,0 & \\
\hline
\end{tabular}

Notes: *Kruskal-Wallis/Dunn test. DIQ, interquartile deviation; P25/P75, 25th and 75th percentiles; CV, coefficient of variation; ${ }^{\dagger}$ Statistically significant. Equal superscript letters indicate the groups that showed statistically significant differences from each other.

Table 3 Severity Category According to the Shwachman-Kulckycki Score Among the Studied Groups

\begin{tabular}{|l|l|l|l|}
\hline \multirow{2}{*}{ Gravity } & \multicolumn{2}{|l|}{ Groups } & P-value* \\
\cline { 2 - 4 } & $\begin{array}{l}\text { Chronic Infection } \\
\text { n=23 (\%) }\end{array}$ & $\begin{array}{l}\text { Intermittent Infection } \\
\mathbf{n = 2 6}(\%)\end{array}$ & $\begin{array}{l}\text { Infection-Free } \\
\mathbf{n = 6 3}(\%)\end{array}$ \\
\hline Excellent & $0(0,0)^{\downarrow}$ & $12(46,2)$ & $30(47,6)^{\uparrow}$ \\
Good & $05(21,8)$ & $09(34,6)$ & $23(36,5)$ \\
Mild & $12(52,2)^{\uparrow}$ & $03(11,5)$ & $09(12,3)^{\downarrow}$ \\
Moderate & $03(13,0)$ & $02(7,7)$ & $01(1,6)^{\downarrow}$ \\
Severe & $03(13,0)^{\uparrow}$ & $0(0,0)$ & $0(0,0)^{\downarrow}$ \\
\hline
\end{tabular}

Notes: ${ }^{*}$ G-test of independence/Chi-Square Residue Analysis. ${ }^{\dagger}$ Statistically significant. ${ }^{\perp}$ Frequency lower than expected at random. ${ }^{\dagger}$ Frequency higher than expected at random.

Of the 49 patients with a positive culture for $P$. aeruginosa, 39 had data on spirometry and 57 infection-free patients performed the test. Table 4 presents the comparison of the spirometric profile among the investigated groups. It was observed that patients with chronic infection had $\mathrm{FEV}_{1}$, FVC and $\mathrm{FEF}_{25-75 \%}$ values significantly lower than those with intermittent infection and control group ( $p<0.0001, p$ $<0.0001$ and $p=0.0003$, respectively), with no difference in the spirometric profile among patients from other groups. The Tiffenau Index $\left(\mathrm{FEV}_{1} / \mathrm{FVC}\right)$ was similar between the three groups ( $p=0.0660$ ), while $\mathrm{FEF}_{25-75 \%}$ parameter was the most variable among all groups.

The prevalence of exos, exoU, exoT and exo $Y$ genes among the 49 isolates of $P$. aeruginosa were $97.9 \%$ (n =48), 63.2\% (n =31), 95.9\% $(\mathrm{n}=47)$ and 97.9\% ( $\mathrm{n}=48)$, respectively. The $\operatorname{exoS}^{+} / \mathrm{exoU}^{+}$virulotype was detected in $61.2 \%(\mathrm{n}=30)$ of isolates. There was a significantly higher frequency of cases of intermittent infection in the presence of exoS $S^{+} / \operatorname{exoU}^{+}$virulotype and cases of chronic infection in the presence of exoS $/$ exoU (Table $5 / p=0.0087$ ). No significant association between T3SS virulotypes and colonies morphology was observed (Table $5 / p=0.8163$ ).

The individual analysis of the Shwachman-Kulckycki score categories revealed that patients infected with $P$. aeruginosa harboring exoS ${ }^{+} /$exoU virulotype obtained lower scores in "general activity" $(p=0.0232)$, "physical examination" $(p<0.0001)$ and "radiological findings" ( $p$ 
Table 4 Spirometric Data of CF Patients According to Infection Status

\begin{tabular}{|c|c|c|c|c|}
\hline \multirow[t]{2}{*}{ Variable } & \multicolumn{3}{|l|}{ Groups } & \multirow[t]{2}{*}{ p-value* } \\
\hline & $\begin{array}{l}\text { Chronic Infection } \\
n=18\end{array}$ & $\begin{array}{l}\text { Intermittent Infection } \\
n=2 \text { I }\end{array}$ & $\begin{array}{l}\text { Infection-Free } \\
n=57\end{array}$ & \\
\hline \multicolumn{5}{|l|}{$\mathrm{FEV}_{1}, \%$} \\
\hline Min. - Max. & $18,0-124,0$ & $30,0-121,0$ & $31,0-136,0$ & $<0,000 \mathrm{I}^{\dagger}$ \\
\hline Median (DIQ) & $43,0(5 I, 0)^{a, b}$ & $86,0(32,0)^{\mathrm{a}}$ & $92,0(24,3)^{\mathrm{b}}$ & \\
\hline P25/P75 & $28,0 / 79,0$ & $70,0 / 102,0$ & $79,7 / 104,0$ & \\
\hline $\mathrm{CV} \%$ & 57,4 & 30,4 & 22,0 & \\
\hline \multicolumn{5}{|l|}{ FVC, \% } \\
\hline Min. - Max. & $22,0-132,0$ & $42,0-133,0$ & $45,0-140,0$ & $<0,000 \mathrm{I}^{\dagger}$ \\
\hline Median (DIQ) & $54,0(37,0)^{a, b}$ & $102,0(29,5)^{\mathrm{a}}$ & $102,0(25,5)^{b}$ & \\
\hline $\mathrm{P} 25 / \mathrm{P} 75$ & $44,0 / 81,0$ & $80,5 / 110,0$ & $87,0 / 112,5$ & \\
\hline $\mathrm{CV} \%$ & 46,4 & 28,4 & 20,1 & \\
\hline \multicolumn{5}{|l|}{$\mathrm{FEV}_{\mathrm{I}} / \mathrm{FVC}, \%$} \\
\hline Min. - Max. & $55,0-97,0$ & $72,0-108,0$ & $65,0-109,0$ & 0,0660 \\
\hline Median (DIQ) & $82,0(25,0)$ & $89,0(25,0)$ & $89,0(11,0)$ & \\
\hline P25/P75 & $72,0 / 97,0$ & $83,0 / 108,0$ & $84,0 / 95,0$ & \\
\hline $\mathrm{CV} \%$ & 16,3 & 9,1 & 10,4 & \\
\hline \multicolumn{5}{|l|}{$\mathrm{FEF}_{25-75}, \%$} \\
\hline Min. - Max. & $10,0-120,0$ & $13,0-155,0$ & $11,0-156,0$ & $0,0003^{\dagger}$ \\
\hline Median (DIQ) & $30,0(59,0)^{a, b}$ & $86,0(47,0)^{\mathrm{a}}$ & $86,0(33,5)^{b}$ & \\
\hline P25/P75 & $16,0 / 75,0$ & $63,0 / 110,0$ & $67,0 / 100,5$ & \\
\hline $\mathrm{CV} \%$ & $8 I, 4$ & 45,8 & 34,7 & \\
\hline
\end{tabular}

Notes: *Kruskal-Wallis/Dunn test. FEVI: forced expiratory volume in the first second. FVC: forced vital capacity. FEF 25-75: forced expiratory flow. DIQ, interquartile deviation. P25/P75: 25th and 75th percentiles. CV, coefficient of variation. ${ }^{\dagger}$ Statistically significant. Equal superscript letters indicate the groups that showed statistically significant differences from each other.

Table 5 Association of T3SS Virulotypes with Infection Profile and Colony Morphology

\begin{tabular}{|c|c|c|c|c|}
\hline \multirow[t]{2}{*}{ Profile } & \multicolumn{3}{|l|}{ Virulotype } & \multirow[t]{2}{*}{ p-value* } \\
\hline & $\begin{array}{l}\operatorname{exoS}^{+} / \operatorname{exoU}^{+} \\
n=30(\%)\end{array}$ & $\begin{array}{l}\operatorname{exoS}^{+} / \operatorname{exoU}^{-} \\
\mathrm{n}=18 \text { (\%) }\end{array}$ & $\begin{array}{l}\operatorname{exoS}^{-} / \operatorname{exoU}^{+} \\
\mathrm{n}=\mathrm{I}(\%)\end{array}$ & \\
\hline \multicolumn{5}{|l|}{ Groups } \\
\hline Chronic infection & $9(30,0)^{\downarrow}$ & $14(77,8)^{\uparrow}$ & $0(0,0)$ & $0,0087^{\dagger}$ \\
\hline Intermittent infection & $21(70,0)^{\uparrow}$ & $4(22,2)^{\downarrow}$ & $I(100)$ & \\
\hline \multicolumn{5}{|l|}{ Morphology } \\
\hline Mucoid & $7(23,4)$ & $8(44,4)$ & $0(0,0)$ & 0,8163 \\
\hline Non-mucoid & $22(73,3)$ & $9(50)$ & I (100) & \\
\hline Both & I $(3,3)$ & I $(5,6)$ & $0(0,0)$ & \\
\hline
\end{tabular}

Notes: *G-test of independence/Chi-Square Residue Analysis. ${ }^{\dagger}$ Statistically significant. ${ }^{\perp}$ Frequency lower than expected at random. ${ }^{\dagger}$ Frequency higher than expected at random.

$<0.0001)$ when compared to infection-free patients. Similarly, the scores for "physical examination" ( $p$ $<0.0001)$ and "radiological findings" $(p<0.0001)$ were lower in patients with $P$. aeruginosa harboring exo $S^{+} /$ exo $U^{+}$virulotype when compared to infection-free patients (Table 6).
Regarding the spirometric data, the $\mathrm{FEV}_{1}, \mathrm{FVC}$ and $\mathrm{FEF}_{25-75 \%}$ values were significantly lower in the presence of the exoS $S^{+} / \operatorname{exo} U$ virulotype when compared to infection-free patients ( $p=0.0005, p=0.0007$ and $p=0.0067$, respectively). The Tiffenau Index $\left(\mathrm{FEV}_{1} / \mathrm{FVC}\right)$ was similar between the three groups $(p=0.1473)$, while $\mathrm{FEF}_{25-75 \%}$ 
Table 6 Association of Shwachman-Kulckycki Score Categories with T3SS Genotypes and Infection-Free Patients

\begin{tabular}{|c|c|c|c|c|}
\hline Variable & $\begin{array}{l}\operatorname{exoS}^{+} / \mathrm{exoU}^{+} \\
\mathrm{n}=30\end{array}$ & $\begin{array}{l}\operatorname{exoS}^{+} / \mathrm{exoU}^{-} \\
\mathrm{n}=18\end{array}$ & $\begin{array}{l}\text { Infection-Free } \\
n=63\end{array}$ & p-value* \\
\hline \multicolumn{5}{|l|}{ General activity } \\
\hline Min. - Max. & $5,0-25,0$ & $5,0-25,0$ & $15,0-25,0$ & $0,0232^{\dagger}$ \\
\hline Median (DIQ) & $20(5,0)$ & $20,0(7,7)^{a}$ & $25,0(5,0)^{\mathrm{a}}$ & \\
\hline P25/P75 & $20,0 / 25,0$ & $17,3 / 25,0$ & $20,0 / 25,0$ & \\
\hline $\mathrm{CV} \%$ & 22,8 & 28,0 & 13,1 & \\
\hline \multicolumn{5}{|c|}{ Physical examination } \\
\hline Min. - Max. & $5,0-25,0$ & $5,0-25,0$ & $10,0-25,0$ & $<0,000 \mathrm{I}^{\dagger}$ \\
\hline Median (DIQ) & $20,0(10,0)^{\mathrm{a}}$ & $15,0(3,5)^{b}$ & $20,0(5,0)^{a, b}$ & \\
\hline P25/P75 & $15,0 / 25,0$ & $15,0 / 18,5$ & $20,0 / 25,0$ & \\
\hline CV\% & 30,2 & 28,5 & 18,0 & \\
\hline \multicolumn{5}{|l|}{ Nutritional status } \\
\hline Min. - Max. & $10,0-25,0$ & $10,0-25,0$ & $10,0-25,0$ & 0,2394 \\
\hline Median (DIQ) & $22,5(6,2)$ & $20,0(10,0)$ & $25,0(5,0)$ & \\
\hline $\mathrm{P} 25 / \mathrm{P} 75$ & $18,8 / 25,0$ & $15,0 / 25,0$ & $20,0 / 25,0$ & \\
\hline $\mathrm{CV} \%$ & 27,4 & 25,3 & 20,7 & \\
\hline \multicolumn{5}{|c|}{ Radiological findings } \\
\hline Min. - Max. & $5,0-20,0$ & $5,0-20,0$ & $10,0-25,0$ & $<0,000 \mathrm{I}^{\dagger}$ \\
\hline Median (DIQ) & $15,0(10,0)^{\mathrm{a}}$ & $15,0(8,0)^{b}$ & $20,0(5,0)^{a, b}$ & \\
\hline $\mathrm{P} 25 / \mathrm{P} 75$ & $10,0 / 20,0$ & $10,0 / 18,0$ & $15,0 / 20,0$ & \\
\hline $\mathrm{CV} \%$ & 32,8 & 32,5 & 21,3 & \\
\hline
\end{tabular}

Notes: *Kruskal-Wallis/Dunn test. DIQ, interquartile deviation. P25/P75: 25th and 75th percentiles. CV, coefficient of variation. ${ }^{\dagger}$ Statistically significant. Equal superscript letters indicate the groups that showed statistically significant differences from each other.

parameter was the most variable among the compared groups (Table 7).

Considering only patients with $P$. aeruginosa chronic infection, significantly lower $\operatorname{FEV}_{1}(p<0.0001)$ and $\mathrm{FEF}_{25-75 \%}(p=0.0004)$ values were observed associated with $\operatorname{exoS} /$ exoU virulotype when compared to infectionfree patients. In addition, FVC $(p<0.0001)$ and overall Shwachman-Kulcky severity score $(p<0.0001)$ were significantly lower in patients with exoS $S^{+}$exoU virulotype when compared with exoS $S^{+} /$exoU $^{+}$virulotype and infection-free groups. The Tiffenau Index was similar among the three groups tested ( $\mathrm{p}=0.0669)$ (Table 8 ).

\section{Discussion}

The findings in this study regarding the percentage of chronic infection were lower than those previously reported, since it is expected that $60-80 \%$ of adults become chronically infected. ${ }^{6}$ However, the presence of chronically infected children rises concern (one, with associated with exoS $S^{+} / \operatorname{exo} U^{+}$virulotype, and two to $\operatorname{exoS}^{+}$/ exoU virulotype), since in early childhood $P$. aeruginosa infection occurs intermittently and is eliminated with antimicrobial therapy. ${ }^{14}$ In addition, persistence in children under 2 years of age increases morbidity and mortality in the first 10 years after diagnosis of infection chronicity when associated with Staphylococcus aureus. Thus, this chronic infection is the highest predictor of morbidity and mortality (2.6 times higher than those not infected). ${ }^{4}$ This fact demonstrates the importance of microbiological monitoring of patients' sputum and the early introduction of antibiotics when initial and intermittent infections are detected in the first months of life. The diagnosis at the center studied was late since many patients joined the $\mathrm{CF}$ program before the implementation of neonatal screening in Pará state. The delay in diagnosis must also have contributed to the onset of chronic infection, highlighting the importance of neonatal screening. ${ }^{1}$

Regardless of the presented virulotype, the number of annual exacerbations was significantly higher among patients with chronic infection. In accordance with our findings, previous studies have also demonstrated decreasing in spirometric values after episodes of exacerbations (Table 2). ${ }^{27}$ However, the previous association of the exoU with a higher risk of exacerbation in patients with noncystic fibrosis bronchiectasis could not be established in our CF study population. ${ }^{28}$ 
Table 7 Association of Spirometric Data with T3SS Genotypes and Infection-Free Patients

\begin{tabular}{|c|c|c|c|c|}
\hline \multirow[t]{2}{*}{ Spirometric Data } & \multicolumn{2}{|l|}{ Virulotype } & \multirow{2}{*}{$\begin{array}{l}\text { Infection-Free } \\
n=57\end{array}$} & \multirow[t]{2}{*}{ p-value* } \\
\hline & $\begin{array}{l}\operatorname{exoS}^{+} / \operatorname{exoU}^{+} \\
n=24\end{array}$ & $\begin{array}{l}\operatorname{exoS}^{+} / \operatorname{exoU}^{-} \\
\mathrm{n}=14\end{array}$ & & \\
\hline \multicolumn{5}{|l|}{$\mathrm{FEV}_{1}, \%$} \\
\hline Min. - Max. & $18,0-124,0$ & $|8,0-12|, 0$ & $31,0-136,0$ & $0,0005^{\dagger}$ \\
\hline Median (DIQ) & $82,5(54,3)$ & $49,0(51,0)^{\mathrm{a}}$ & $92,0(24,3)^{\mathrm{a}}$ & \\
\hline $\mathrm{P} 25 / \mathrm{P} 75$ & $44,8 / 99,00$ & $28,0-79,0$ & $79,7 / 104,0$ & \\
\hline CV\% & 39,2 & 56,6 & 22,0 & \\
\hline \multicolumn{5}{|l|}{ FVC, \% } \\
\hline Min. - Max. & $22,0-132,0$ & $22,0-133,0$ & $45,0-140,0$ & $0,0007^{\dagger}$ \\
\hline Median (DIQ) & $92,0(51,8)$ & $54,0(43,0)^{\mathrm{a}}$ & $102,0(25,5)^{\mathrm{a}}$ & \\
\hline P25/P75 & $56,5 / 108,3$ & $47,0-90,0$ & $87,0 / 112,5$ & \\
\hline $\mathrm{CV} \%$ & 35,5 & 46,6 & 20,1 & \\
\hline \multicolumn{5}{|l|}{$\mathrm{FEV}_{\mathrm{l}} / \mathrm{FVC}, \%$} \\
\hline Min. - Max. & $55,0-108,0$ & $57,0-99,0$ & $65,0-109,0$ & 0,1473 \\
\hline Median (DIQ) & $87,0(1 I, 0)$ & $83,0(19,0)$ & $89,0(11,0)$ & \\
\hline P25/P75 & $82,0 / 93,0$ & $72,0-91,0$ & $84,0 / 95,0$ & \\
\hline $\mathrm{CV} \%$ & 12,0 & 15,6 & 10,4 & \\
\hline \multicolumn{5}{|l|}{$\mathrm{FEF}_{25-75}, \%$} \\
\hline Min. - Max. & $10,0-143,0$ & $10,0-150,0$ & $11,0-156,0$ & $0,0067^{\dagger}$ \\
\hline Median (DIQ) & $81,5(65,3)$ & $30,0(66,0)^{\mathrm{a}}$ & $86,0(33,5)^{\mathrm{a}}$ & \\
\hline $\mathrm{P} 25 / \mathrm{P} 75$ & $30,0-95,8$ & $21,0-87,0$ & $67,0 / 100,5$ & \\
\hline $\mathrm{CV} \%$ & 53,9 & 83,1 & 34,7 & \\
\hline
\end{tabular}

Notes: *Kruskal-Wallis/Dunn test. FEVI: forced expiratory volume in the first second. FVC: forced vital capacity. FEF 25-75: forced expiratory flow. DIQ, interquartile deviation. P25/P75: 25th and 75th percentiles. CV, coefficient of variation. 'Statistically significant. Equal superscript letters indicate the groups that showed statistically significant differences from each other.

P. aeruginosa clinical isolates exhibit variations in genotypic and phenotypic virulence profiles, which influence infection severity and clinical outcomes. ${ }^{13,29}$ Regarding T3SS-related genes, several authors have shown those variations analyzing isolates from distinct setting, including individual, environmental and clinical isolates, demonstrating the important role in the evolution of human disease and persistence in high-pressure settings. ${ }^{16,17,30,31}$ In CF P. aeruginosa isolates, the prevalence of these genes is also variable. In a study conducted at an Iranian CF Center evaluating 143 $P$. aeruginosa isolates, the exoS was the most prevalent $(90.2 \%)$, followed by exoU (39.8\%), in addition to low frequencies of exoT (28.6\%) and exoY $(25.2 \%){ }^{7}$ In a Bulgarian study, 42 CF P. aeruginosa isolates the presence of exoS genes was observed in $52.4 \%$ and exoU in $28.6 \%$. The exoS $S^{+}$exo $U^{+}$virulotype was present in $11.4 \%$ among the 202 isolates studied, including $\mathrm{CF}$ and non-CF isolates. ${ }^{30}$ Overall, previously reported frequencies were lower than those found in the present study, in which the prevalence of virulence genes was exoS (97.9\%), exoU (63.2\%), exoT (95.9\%) and exoY (97.9\%).
Evidence observed in previous studies indicates the mutual exclusion of exoS/exoU genes, being the exoS $S^{+}$/ exo $U^{+}$virulotype rarely reported. However, in our study, a high prevalence of exoS $S^{+} / e x U^{+}$virulotype isolates was observed (61.2\%), mainly, in the initial phase of infection and significantly less frequency among chronically infected patients. In a study by $\mathrm{Hu}$ et al ${ }^{14}$ exoU $U^{+}$strains were observed in the initial and subsequent infections of respiratory specimens in children up to 5 years old diagnosed with CF and followed up after the neonatal screening. Similarly, the obtained data demonstrate the exoS $S^{+}$/ exo $U^{+}$virulotype in a higher frequency among intermittent infections and in patients significantly younger than those from other groups (Table 5).

According to the Shwachman-Kulckycki score, the high frequency of exoS $S^{+} / \operatorname{exo}^{+}$virulotype was associated with radiological changes and physical examination findings when compared to infection-free patients (Table 6). This fact could be better understood evaluating ExoU secretion since this is a marker of highly virulent strains associated with specific sites to immunocompromised 
Table 8 Association of Spirometric Data and Shwachman-Kulckycki Score of Patients with P. Aeruginosa Chronic Infection with T3SS Genotypes and Infection-Free Patients

\begin{tabular}{|c|c|c|c|c|}
\hline \multirow[t]{2}{*}{ Variable } & \multicolumn{2}{|c|}{ Virulotypes of Chronically Infected Patients } & \multirow{2}{*}{$\begin{array}{l}\text { Infection-Free } \\
n=57\end{array}$} & \multirow[t]{2}{*}{ p-value* } \\
\hline & $\begin{array}{l}\operatorname{exoS}^{+} / \operatorname{exoU}^{+} \\
n=07\end{array}$ & $\begin{array}{l}\operatorname{exoS}^{+} / \operatorname{exoU}^{-} \\
\mathrm{n}=12\end{array}$ & & \\
\hline \multicolumn{5}{|l|}{$\mathrm{FEV}_{1}, \%$} \\
\hline Min. - Max. & $18,0-124,0$ & $18,0-100,0$ & $31,0-136,0$ & $<0,0001^{\dagger}$ \\
\hline Median (DIQ) & $43,0(54,0)$ & $44,0(40,2)^{a}$ & $92,0(24,3)^{a}$ & \\
\hline $\mathrm{P} 25 / \mathrm{P} 75$ & $29,0 / 83,0$ & $27,3 / 67,5$ & $79,7 / 104,0$ & \\
\hline $\mathrm{CV} \%$ & 64,5 & 51,9 & 22,0 & \\
\hline \multicolumn{5}{|l|}{ FVC, \% } \\
\hline Min. - Max. & $22,0-132,0$ & $22,0-104,0$ & $45,0-140,0$ & $<0,0001^{\dagger}$ \\
\hline Median (DIQ) & $78,0(48,0)^{\mathrm{a}}$ & $52,0(32,0)^{\mathrm{s}}$ & $102,0(25,5)^{\mathrm{a}, \mathrm{b}}$ & \\
\hline $\mathrm{P} 25 / \mathrm{P} 75$ & $38,0 / 86,0$ & $44,8 / 76,8$ & $87,0 / 112,5$ & \\
\hline $\mathrm{CV} \%$ & 53,3 & $4 I, 0$ & 20,1 & \\
\hline \multicolumn{5}{|l|}{$\mathrm{FEV}_{\mathrm{l}} / \mathrm{FVC}, \%$} \\
\hline Min. - Max. & $55,0-97,0$ & $57,0-96,0$ & $65,0-109,0$ & 0,0669 \\
\hline Median (DIQ) & $82,0(17,0)$ & $82,5(20,0)$ & $89,0(11,0)$ & \\
\hline $\mathrm{P} 25 / \mathrm{P} 75$ & $77,0 / 94,0$ & $70,5 / 90,5$ & $84,0 / 95,0$ & \\
\hline $\mathrm{CV} \%$ & 17,3 & 16,4 & 10,4 & \\
\hline \multicolumn{5}{|l|}{$\mathrm{FEF}_{25-75}, \%$} \\
\hline Min. - Max. & $10,0-120,0$ & $10,0-88,0$ & $11,0-156,0$ & $0,0004^{\dagger}$ \\
\hline Median (DIQ) & $20,0(80,0)$ & $30,0(48,2)^{a}$ & $86,0(33,5)^{\mathrm{a}}$ & \\
\hline $\mathrm{P} 25 / \mathrm{P} 75$ & $16,0 / 96,0$ & $|2,8 / 6|, 0$ & $67,0 / 100,5$ & \\
\hline $\mathrm{CV} \%$ & 90,3 & 73,5 & 34,7 & \\
\hline Overall Severity Score & $n=09$ & $n=14$ & $n=63$ & \\
\hline Min. - Max. & $25,0-85,0$ & $25,0-85,0$ & $50,0-100,0$ & $<0,000 \mathrm{I}^{\dagger}$ \\
\hline Median (DIQ) & $65,0(25,0)^{\mathrm{a}}$ & $65,0(11,8)^{b}$ & $85,0(15,0)^{a, b}$ & \\
\hline $\mathrm{P} 25 / \mathrm{P} 75$ & $47,5 / 72,5$ & $59,5 / 71,3$ & $75,0 / 90,0$ & \\
\hline $\mathrm{CV} \%$ & 29,7 & 24,6 & 13,5 & \\
\hline
\end{tabular}

Notes: *Kruskal-Wallis/Dunn test. DIQ, interquartile deviation. P25/P75: 25th and 75th percentiles. CV, coefficient of variation. ${ }^{\dagger}$ Statistically significant. Equal superscript letters indicate the groups that showed statistically significant differences from each other.

patients. ${ }^{13}$ Also, in chronically infected patients, the

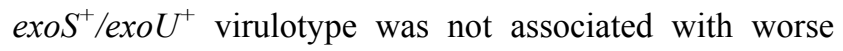
clinical data when compared to the $\operatorname{exoS}^{+} /$exoU $U$ virulotype (Table 8); however, such analysis was limited given the reduced number of $\operatorname{exoS}^{+} / \mathrm{exoU}^{+}$virulotype in chronic infection. Other studies demonstrate that ExoU-producing strains are poorly represented in persistent CF infection, which might be related to: (I) deletion over time, probably due to treatment with anti-pseudomonal drugs, which causes a selection against ExoU-producing $P$. aeruginosa with loss of exoU gene; (II) the deficiency in the secretion of ExoU contributes to the evasion of the immune system and promotes chronic infection; and finally, (III) the previous evidenced role played by ExoS in the pathogenesis of $\mathrm{CF}$, selecting strains harboring exoS and allowing $P$. aeruginosa to colonize and persist in the lung of $\mathrm{CF}$ patients. ${ }^{14,16,32}$

In general, $P$. aeruginosa isolates from adults and older children with $\mathrm{CF}$ and chronically infected presents the $\mathrm{exoS}^{+} /$ exo $U$ virulotype, ${ }^{13}$ in agreement with our findings (Tables 2 and 5). This virulotype was related to lower values in spirometric data $\left(\mathrm{FEV}_{1}, \mathrm{FVC}\right.$ and $\left.\mathrm{FEF}_{25-75 \%}\right)$ and severity score in the categories that directly express pulmonary impairment such as physical examination, general activity and radiological findings (Tables 6 and 7). This is a worrying fact, since the presence of $P$. aeruginosa in patients with CF causes a decrease in the radiological score and Tiffenau Index $\left(\mathrm{FEV}_{1} /\right.$ FVC), ${ }^{4}$ with the latter being similar among the studied groups (Table 7). In an Australian longitudinal study, 77 (83.7\%) were $\operatorname{exoS}^{+}$, where strains from initial infections 
secreted five times more ExoS than those from subsequent infections. However, there was a diminishing in ExoS secretion with increasing age, in line with the hypothesis that bacterial persistence in chronic infection leads to the deregulation of virulence factors; despite this, the formation of antibodies against T3SS still occurs, suggesting its role in the pathogenesis of lung injury. ${ }^{14,32}$ Among environmental samples from the same study, $60.7 \%$ presented exoS, and $39.1 \%$ were exoU. ${ }^{14}$ It is important to note that the strains of $\mathrm{CF}$ patients are mostly environmental, in which exo $U^{+}$is more prevalent.

ExoS is the major virulence factor associated with invasion, colonization and spread in chronic lung infections and burns. ${ }^{31}$ Regardless of the infection status, exoS had a higher prevalence, with only one isolate not harboring such a gene, in addition to a higher frequency than exo $U$ in the evaluated isolates, indicating an important role in lung infection. Feltman et al ${ }^{16}$ reported an exoS prevalence of $85 \%(17 / 20)$ in respiratory isolates from $\mathrm{CF}$ patients; however, in isolates from other clinical sources, the prevalence varied with statistical significance in relation to isolates from bloodstream infection. In environmental isolates, $80 \%(16 / 20)$ were exo $S^{+}$, suggesting that ExoS is not essential for $P$. aeruginosa survival in nature. exoU was detected in $10 \%(2 / 20)$ of $\mathrm{CF}$ isolates, less frequent than in the other studied and with a significant difference in relation to isolates from bloodstream infection and wound. exoU was detected in $20 \%(4 / 20)$ of the environmental samples. None of the isolates demonstrated exoS $S^{+} /$exo $^{+}$virulotype. exoT was present in $100 \%$ of samples and exo $Y$ in $90 \%$ of CF samples, with a significant difference in relation to urine samples. In a larger study comprising $\mathrm{CF}$ and non-CF $P$. aeruginosa respiratory isolates, the prevalence of exoS was $90 \%(36 / 40)$ and $73 \%$ (29/40) while exoU was $8 \%(3 / 40)$ and $25 \%(10 / 40)$, respectively, with a significant difference. ${ }^{16}$ Lanotte et al ${ }^{33}$ also observed the presence of exoS among $93.8 \%$ of $81 \mathrm{CF}$ isolates, with a significant difference when compared to the other 81 samples from four different clinical origins.

Once colonized, the patient often remains with the same strain for years and it is conceivable that T3SS genes were deleted after years of growth within the $\mathrm{CF}$ lung or that it was possible for the ExoS and ExoU to antagonize, performing a selective pressure on $P$. aeruginosa strains to delete one of the encoding genes. ${ }^{34}$ This fact is in agreement with a cohort with analysis by PFGE and MLST of clinical isolates of $P$. aeruginosa from CF patients, in which $87 \%$ had concordant fingerprints for up to 25 years. ${ }^{35}$ Also, indistinguishable strains were observed in $77 \%$ of patients with chronic infection in a longitudinal study for 32 months. ${ }^{36}$

Furthermore, previous reports showed that $90 \%$ of ExoU-producing $P$. aeruginosa strains were associated with a severe infection in patients with pneumonia associated with mechanical ventilation. ${ }^{37}$ Thus, the spread and emergence of multidrug-resistant $P$. aeruginosa strains capable of producing ExoU is a challenge in hospital settings and CF referral centers, given the large number of hospitalizations and cycles of antibiotic therapy that these patients may undergo throughout life limiting antimicrobial therapeutic options. Therefore, detection of the exoU gene can predict early clinical severity, aiding in the management, antimicrobial therapy and adoption of cross infection control measures.

\section{Conclusions}

In conclusion, compared to previous reports, the atypical exoS $S^{+} / e x o U^{+}$virulotype was frequently found among our $P$. aeruginosa population, mainly associated with intermittent infections, changes in the physical, spirometric and radiological findings and related to a greater occurrence of pulmonary exacerbations, however without worse clinical results associated with chronic infection. The presence of this atypical virulotype did not determine a worse clinical picture, as reported in other infection sites, such as isolated from the bloodstream infections and in pneumonia associated with mechanical ventilation. The exoS $/$ exoU virulotype was associated with chronic infections and worse clinical results, including a significantly lower spirometric profile. Finally, the importance of $P$. aeruginosa virulotypes detection has been demonstrated, since virulence factors play a decisive role in pulmonary impairment, clinical progression and disease severity in CF patients.

\section{Acknowledgments}

We thank the technicians of the Laboratory of Special Pathogens (SABMI/IEC).

\section{Funding}

This research was supported by funding from Fundação de Amparo à Pesquisa do Pará/Universidade do Estado do Pará (FAPESPA/UEPA) [Cooperation grant No004/2019], Programa Institucional de Bolsas de Iniciação Científica/ Fundação Amazônia Paraense de Amparo à Pesquisa/ Universidade do Estado do Pará (FAPESPA/UEPA) [Cooperation grant No01/2017/PPGBPA], Programa 
Institucional de Bolsas de Iniciação Científica/Fundação Amazônia Paraense de Amparo à Pesquisa/Universidade do Estado do Pará (FAPESPA/UEPA) [Cooperation grant No002/2019/Graduação], Programa Institucional de Bolsas de Iniciação Científica/Instituto Evandro Chagas Conselho Nacional de Desenvolvimento Científico e Tecnológico (PIBIC/IEC/CNPq) and Instituto Evandro Chagas/Ministério da Saúde/Secretaria de Vigilância em Saúde (IEC/MS/SVS).

\section{Disclosure}

The authors report no conflicts of interest in this work.

\section{References}

1. Athanazio RA, da Silva Filho LVRF, Vergara AA, et al. Brazilian guidelines for the diagnosis and treatment of cystic fibrosis. $J$ Bras Pneumol. 2017;43(3):219-245.

2. Marson FAL, Hortencio TDR, Aguiar KCA, et al. Demographic, clinical, and laboratory parameters of cystic fibrosis during the last two decades: a comparative analysis. BMC Pulm Med. 2015;15(3). doi:10.1186/1471-2466-15-3.

3. Elborn JS. Cystic fibrosis. Lancet. 2016;388(10059):2519-2531. doi:10.1016/S0140-6736(16)00576-6

4. Silva Filho LVRFD, Ferreira FDA, Reis FJC, et al. Infecção por Pseudomonas aeruginosa em pacientes com fibrose cística: evidências científicas sobre o impacto clínico, diagnóstico e tratamento. J Bras Pneumol. 2013;39(4):495-512. doi:10.1590/S180637132013000400015

5. Crull MR, Ramos KJ, Caldwell E, Mayer-Hamblett N, Aitken ML, Goss CH. Change in Pseudomonas aeruginosa prevalence in cystic fibrosis adults over time. BMC Pulm Med. 2016;16(1):1-7. doi:10.1186/s12890-016-0333-y

6. Parkins MD, Somayaji R, Waters VJ. Epidemiology, biology, and impact of clonal Pseudomonas aeruginosa infections in cystic fibrosis. Clin Microbiol Rev. 2018;31(4).

7. Pournajaf A, Razavi S, Irajian G, et al. Integron types, antimicrobial resistance genes, virulence gene profile, alginate production and biofilm formation in Iranian cystic fibrosis Pseudomonas aeruginosa isolates. Infez Med. 2018;26(3):226-236.

8. Vidya P, Smith L, Beaudoin T, et al. Chronic infection phenotypes of Pseudomonas aeruginosa are associated with failure of eradication in children with cystic fibrosis. Eur J Clin Microbiol Infect Dis. 2016;35 (1):67-74. doi:10.1007/s10096-015-2509-4

9. Saiman L, Siegel JD, LiPuma JJ, et al. Infection prevention and control guideline for cystic fibrosis: 2013 update. Infect Control Hosp Epidemiol. 2014;35(S1):s1-s67. doi:10.1086/676882

10. Lee AC, Jones AL. Multi-resistant Pseudomonas aeruginosa ST235 in cystic fibrosis. Paediatr Respir Rev. 2018;27:18-20. doi:10.1016/j. prrv.2018.05.009

11. Gellatly SL, Hancock RE. Pseudomonas aeruginosa: new insights into pathogenesis and host defenses. Pathog Dis. 2013;67(3):159173. doi:10.1111/2049-632X.12033

12. Harmer CJ, Triccas JA, Hu H, et al. Pseudomonas aeruginosa strains from the chronically infected cystic fibrosis lung display increased invasiveness of A549 epithelial cells over time. Microb Pathog. 2012;53(1):37-43. doi:10.1016/j.micpath.2012.03.011

13. Sawa T, Shimizu M, Moriyama K, Wiener-Kronish JP. Association between Pseudomonas aeruginosa type III secretion, antibiotic resistance, and clinical outcome: a review. Crit Care. 2014;18(6):668. doi:10.1186/s13054-014-0668-9
14. Hu H, Harmer C, Anuj S, et al. Type 3 secretion system effector genotype and secretion phenotype of longitudinally collected Pseudomonas aeruginosa isolates from young children diagnosed with cystic fibrosis following newborn screening. Clin Microbiol Infect. 2013;19(3):266-272. doi:10.1111/j.14690691.2012.03770.x

15. Bradbury RS, Roddam LF, Merritt A, Reid DW, Champion AC. Virulence gene distribution in clinical, nosocomial and environmental isolates of Pseudomonas aeruginosa. J Med Microbiol. 2010;59 (8):881-890. doi:10.1099/jmm.0.018283-0

16. Feltman H, Schulert G, Khan S, Jain M, Peterson L, Hauser AR. Prevalence of type III secretion genes in clinical and environmental isolates of Pseudomonas aeruginosa. Microbiology. 2001;147 (10):2659-2669. doi:10.1099/00221287-147-10-2659

17. Horna G, Amaro C, Palacios A, Guerra H, Ruiz J. High frequency of the exoUt/exoS+ genotype associated with multidrug-resistant "high-risk clones" of Pseudomonas aeruginosa clinical isolates from Peruvian hospitals. Sci Rep. 2019;9(1):1-13. doi:10.1038/ s41598-019-47303-4

18. Morales-Espinosa R, Delgado G, Espinosa LF, et al. Fingerprint analysis and identification of strains ST309 as a potential high risk clone in a Pseudomonas aeruginosa population isolated from children with bacteremia in Mexico City. Front Microbiol. 2017;8:13. doi:10.3389/fmicb.2017.00313

19. Finnan S, Morrissey JP, O'gara F, Boyd EF. Genome diversity of Pseudomonas aeruginosa isolates from cystic fibrosis patients and the hospital environment. J Clin Microbiol. 2004;42(12):5783-5792. doi:10.1128/JCM.42.12.5783-5792.2004

20. Peña C, Cabot G, Gómez-Zorrilla $S$, et al. Influence of virulence genotype and resistance profile in the mortality of Pseudomonas aeruginosa bloodstream infections. Clin Infect Dis. 2015;60(4):539548. doi:10.1093/cid/ciu866

21. El-Solh AA, Hattemer A, Hauser AR, Alhajhusain A, Vora H. Clinical outcomes of type III Pseudomonas aeruginosa bacteremia. Crit Care Med. 2012;40(4):1157-1163. doi:10.1097/CCM.0b013e 3182377906

22. Jabalameli F, Mirsalehian A, Khoramian B, et al. Evaluation of biofilm production and characterization of genes encoding type III secretion system among Pseudomonas aeruginosa isolated from burn patients. Burns. 2012;38(8):1192-1197. doi:10.1016/j.burns.2012. 07.030

23. Shwachman H, Kulczycki LL. Long-term study of one hundred five patients with cystic fibrosis: studies made over a five-to fourteen-year period. AMA J Dis Child. 1958;96(1):6-15. doi:10.1001/archpedi. 1958.02060060008002

24. Pereira C. Sociedade Brasileira de Pneumologia e Tisiologia, Sociedade Brasileira de Pneumologia e Tisiologia. Diretrizes para testes de função pulmonar. J Pneumol. 2002;28(Suppl 3):S1-238.

25. Zhu H, Conibear TC, Bandara R, Aliwarga Y, Stapleton F, Willcox MD. Type III secretion system-associated toxins, proteases, serotypes, and antibiotic resistance of Pseudomonas aeruginosa isolates associated with keratitis. Curr Eye Res. 2006;31(4):297-306. doi:10.1080/02713680500536746

26. Ayres M, Ayres Júnior M, Ayres DL, Santos AS. BioEstat 5.0. Aplicações Estatísticas Nas Áreas Das Ciências Bio-Médicas. Belém (PA): Instituto de Desenvolvimento Sustentável Mamirauá; 2008.

27. Juarez-Colunga E, Rosenfeld M, Zemanick ET, Wagner B. Application of multiple event analysis as an alternative approach to studying pulmonary exacerbations as an outcome measure. $J$ Cyst Fibros. 2020;19(1):114-118. doi:10.1016/j.jcf.2018.12.005

28. Luo RG, Miao XY, Luo LL, Mao B, Yu FY, Xu JF. Presence of pldA and exoU in mucoid Pseudomonas aeruginosa is associated with high risk of exacerbations in non-cystic fibrosis bronchiectasis patients. Clin Microbiol Infect. 2019;25(5):601-606. doi:10.1016/j. cmi.2018.07.008 
29. Lanotte P, Mereghetti L, Lejeune B, Massicot P, Quentin R Pseudomonas aeruginosa and cystic fibrosis: correlation between exoenzyme production and patient's clinical state. Pediatr Pulmonol. 2003;36(5):405-412. doi:10.1002/ppul.10380

30. Mitov I, Strateva T, Markova B. Prevalence of virulence genes among bulgarian nosocomial and cystic fibrosis isolates of Pseudomonas aeruginosa. Braz J Microbiol. 2010;41(3):588-595. doi:10.1590/S1517-83822010000300008

31. Khodayary R, Nikokar I, Mobayen MR, et al. High incidence of type III secretion system associated virulence factors (exoenzymes) in Pseudomonas aeruginosa isolated from Iranian burn patients. BMC Res Notes. 2019;12(1):1-6. doi:10.1186/s13104-019-4071-0

32. Engel J, Balachandran P. Role of Pseudomonas aeruginosa type III effectors in disease. Curr Opin Microbiol. 2009;12(1):61-66. doi:10.1016/j.mib.2008.12.007

33. Lanotte P, Watt S, Mereghetti L, et al. Genetic features of Pseudomonas aeruginosa isolates from cystic fibrosis patients compared with those of isolates from other origins. $J$ Med Microbiol. 2004;53(1):73-81. doi:10.1099/jmm.0.05324-0
34. Römling U, Fiedler B, Boßhammer J, et al. Epidemiology of chronic Pseudomonas aeruginosa infections in cystic fibrosis. J Infect Dis. 1994;170(6):1616-1621. doi:10.1093/infdis/170.6.1616

35. Parkins MD, Glezerson BA, Sibley CD, et al. Twenty-five-year outbreak of Pseudomonas aeruginosa infecting individuals with cystic fibrosis: identification of the prairie epidemic strain. J Clin Microbiol. 2014;52(4):1127-1135. doi:10.1128/JCM.03218-13

36. Logan C, Habington A, Lennon $\mathrm{G}$, et al. Genetic relatedness of Pseudomonas aeruginosa isolates among a paediatric cystic fibrosis patient cohort in Ireland. J Med Microbiol. 2012;61(1):64-70. doi:10.1099/jmm.0.035642-0

37. Hauser AR, Cobb E, Bodí M, et al. Type III protein secretion is associated with poor clinical outcomes in patients with ventilatorassociated pneumonia caused by Pseudomonas aeruginosa. Crit Care Med. 2002;30(3):521-528. doi:10.1097/00003246-200203000-00005
Infection and Drug Resistance

\section{Publish your work in this journal}

Infection and Drug Resistance is an international, peer-reviewed openaccess journal that focuses on the optimal treatment of infection (bacterial, fungal and viral) and the development and institution of preventive strategies to minimize the development and spread of resistance. The journal is specifically concerned with the epidemiology of
Dovepress

antibiotic resistance and the mechanisms of resistance development and diffusion in both hospitals and the community. The manuscript management system is completely online and includes a very quick and fair peerreview system, which is all easy to use. Visit http://www.dovepress.com/ testimonials.php to read real quotes from published authors. 